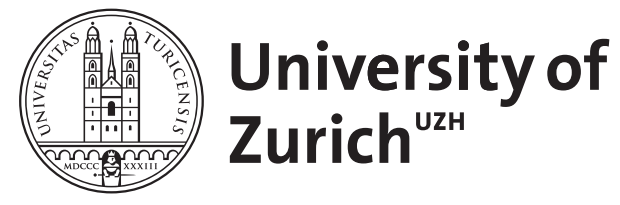

Zurich Open Repository and Archive

University of Zurich

University Library

Strickhofstrasse 39

CH-8057 Zurich

www.zora.uzh.ch

Year: 2008

Impact of traumatic lesions on intracerebral probe positioning

Stover, J F

DOI: https://doi.org/10.1007/s00134-008-1073-0

Posted at the Zurich Open Repository and Archive, University of Zurich

ZORA URL: https://doi.org/10.5167/uzh-10620

Journal Article

Published Version

Originally published at:

Stover, J F (2008). Impact of traumatic lesions on intracerebral probe positioning. Intensive Care Medicine, 34(6):1156-1157.

DOI: https://doi.org/10.1007/s00134-008-1073-0 
John F. Stover

\section{Impact of traumatic lesions on intracerebral probe positioning}

Accepted: 24 January 2008

Published online: 26 March 2008

(C) Springer-Verlag 2008

An author's reply to this comment is available at: http://dx.doi.org/10.1007/ s00134-008-1074-z.

Sir: With great interest I read the work by Longhi et al., who investigated the importance of probe location on brain tissue oxygen tension $\left(\mathrm{ptiO}_{2}\right)$ in patients with different traumatic lesions [1]. The authors address a highly important and difficult issue, as heterogeneous traumatic lesions exhibit regionally and temporally heterogeneous functional and structural alterations. To date, the impact of probe positioning on lesion-specific diagnostic and therapeutic steps remains unanswered.

As shown by Dr. Longhi and colleagues, $\mathrm{ptiO}_{2}$ is reversibly decreased pericontusionally compared to normal-appearing tissue. In general, however, this rather marginal difference will be missed at the bedside. Interestingly, pathologic $\mathrm{ptiO}_{2}$ values were not reflected by abnormal $\mathrm{SjvO}_{2}$, strongly indicating regional heterogeneity and supporting simultaneous measurements at different locations.

In patients with contusions, $\mathrm{ptiO}_{2}$ probes were to be located within the ischemic hypodense pericontusional area. However, the exact probe location remains unclear. Different depth of insertion and distance from the lesions could be important confounding variables, since gray and white matter differ in terms of perfusion and metabolic profile. $\mathrm{ptiO}_{2}$ probes were inserted during initial surgery early after trauma with small pericontusional hypodensity. Over time, contusion growth will encompass the initial hypodense region, expanding its ischemic halo, thus possibly enclosing the inserted probes [2]. This could explain the persistently low $\mathrm{ptiO}_{2}$ values until day 3 after injury [1]. The subsequent significant increase could be related to the resolving contusion with improved pericontusional perfusion due to reduced perilesional edema formation. Serial perfusion CT scans might be helpful in assessing perilesional cerebral perfusion [3].

As clearly shown by the authors, normal-appearing tissue does not guarantee intact perfusion, oxygenation, and metabolism as seen under clinical and experimental conditions $[4,5]$. Although tissue compression induced by epidural and subdural hematoma is reversible upon hematoma removal, metabolic brain injury can persist [4]. Thus, it is important to define "diffuse injury" more closely and consider the actual lesion types which are not differentiated by the Marshall CT classification. This might provide more detailed insight into pathologic $\mathrm{ptiO}_{2}$ values as reflected by a metabolic penumbra zone [6], especially since the majority of patients suffer from different lesions existing simultaneously.

While $\mathrm{ptiO}_{2}$ was collected continuously, other parameters were determined at only two time points per day. Perhaps important alterations were missed. Furthermore, dynamic influences of therapeutic measures were not considered.

All patients were hyperventilated. In patients with contusions and pericontusional ischemia, this could have induced more severe local damage, explaining their lower $\mathrm{ptiO}_{2}$ values during the early phase.

Perhaps patients with focal lesions require higher CPP levels to correct decreased perilesional $\mathrm{ptiO}_{2}$ values. $\mathrm{ptiO}_{2^{-}}$, microdialysis-, and $\mathrm{SjvO}_{2}$-controlled CPP requirements are dynamic and require flexibility. Pathologic changes are also found beyond day 5 .

Regionally heterogeneous alterations in metabolism and perfusion and the duty to protect and not harm the already injured brain force us to gain adequate insight into otherwise occult changes within the brain. This requires introduction of several probes to monitor different regions simultaneously. The future will show whether it may be unethical to confine measurements to only one location following traumatic brain injury.

\section{References}

1. Longhi L, Pagan F, Valeriani V, Magnoni S, Zanier ER, Conte V, Branca V, Stocchetti N (2007) Monitoring brain tissue oxygen tension in brain-injured patients reveals hypoxic episodes in normal-appearing and in peri-focal tissue. Intensive Care Med 33:2136-2142

2. Kroppenstedt SN, Thomale UW, Griebenow M, Sakowitz OW, Schaser KD, Mayr PS, Unterberg AW, Stover JF (2003) Effects of early and late intravenous norepinephrine infusion on cerebral perfusion, microcirculation, brain-tissue oxygenation, and edema formation in brain-injured rats. Crit Care Med 31:2211-2221

3. Wintermark M, van Melle G, Schnyder P, Revelly JP, Porchet F, Regli L, Meuli R, Maeder P, Chioléro R (2004) Admission perfusion CT: prognostic value in patients with severe head trauma. Radiology 232:211-220

4. Engström M, Polito A, Reinstrup P, Romner B, Ryding E, Ungerstedt U, Nordström CH (2005) Intracerebral microdialysis in severe brain trauma: the importance of catheter location. J Neurosurg 102:460-469 
5. Thomale UW, Griebenow M, Mautes A, 6 . Beyer TF, Dohse NK, Stroop R, Sakowitz OW, Unterberg AW, Stover JF (2007) Heterogeneous regional and temporal energetic impairment following controlled cortical impact injury in rats. Neurol Res 29:594-603
. Nilsson OG, Polito A, Säveland H, Ungerstedt U, Nordström CH (2006) Are primary supratentorial intracerebral hemorrhages surrounded by a biochemical penumbra? A microdialysis study. Neurosurgery 59:521-528
J. F. Stover (匹)

University Hospital Zuerich, Surgical Intensive Care Medicine,

Raemistrasse 100, 8006 Zuerich,

Switzerland

e-mail: john.stover@access.unizh.ch 